\title{
PEG 6000-Stimulated Drought Stress Improves the Attributes of In Vitro Growth, Steviol Glycosides Production, and Antioxidant Activities in Stevia rebaudiana Bertoni
}

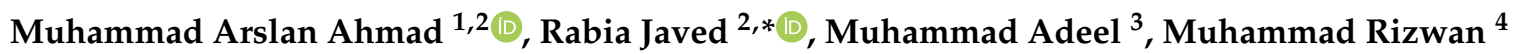 \\ and Yuesuo Yang 1,5,*D \\ 1 Key Lab of Eco-Restoration of Regional Contaminated Environment, Ministry of Education, \\ Shenyang University, Shenyang 110044, China; arslan.slu@gmail.com \\ 2 Department of Tissue Engineering, China Medical University, Shenyang 110122, China \\ 3 Beijing Key Laboratory of Farmland Soil Pollution Prevention and Remediation, College of Resources and \\ Environmental Sciences, China Agricultural University, Beijing 100193, China; Chadee1969@gmail.com \\ 4 Institute of Soil Science, PMAS Arid Agriculture University Rawalpindi, Rawalpindi 46000, Pakistan; \\ muhammadrizwan@webmail.hzau.edu.cn \\ 5 Key Lab of Groundwater and Environment, Ministry of Education, Jilin University, \\ Changchun 130021, China \\ * Correspondence: rabia.javed@ymail.com (R.J.); yangyuesuo@jlu.edu.cn (Y.Y.)
}

Received: 21 October 2020; Accepted: 9 November 2020; Published: 12 November 2020

\begin{abstract}
This study addresses the favourable effects of drought stress imposed by polyethylene glycol (PEG) 6000 on the micropropagated shoots of Stevia rebaudiana. Various concentrations, i.e., 0, 0.5, 1, 2, and 4\% of PEG 6000 were applied to the nodal shoot explants for four weeks, and the influence produced on shoots growth parameters, bioactive steviol glycosides (rebaudioside A and stevioside), and nonenzymatic antioxidant activities (total phenolic content (TPC), total flavonoid content (TFC), total antioxidant capacity (TAC), total reducing power (TRP) and 1,1-diphenyl-2-picrylhydrazyl(DPPH)-free radical scavenging activity (FRSA)) was elucidated. The significantly highest yield (92.4\% direct shoot organogenesis) and secondary metabolites $(2.94 \%$ Reb A, 2.52\% ST, 95.3\% DPPH-FRSA, 15.0\% TPC, $13.0 \mu \mathrm{g} / \mathrm{mg}$ TFC, $22.3 \mu \mathrm{g} / \mathrm{mg}$ TAC, and $19.8 \mu \mathrm{g} / \mathrm{mg}$ TRP) production in response to abiotic stress elicitors was obtained in Murashige and Skoog (MS) medium treatment provided with $4 \%$ of PEG 6000 . The overall trend was significant enhancement of growth dynamics and pharmaceutical compounds from control to $4 \%$ of PEG 6000 concentration as a defensive response against reactive oxygen species (ROS) produced in excess by water deficit. This is a very promising study to be employed in bioreactors to get markedly enhanced content of compounds of medicinal importance in the pharmaceutical market.
\end{abstract}

Keywords: Stevia rebaudiana; steviol glycosides (SGs); antioxidant activities; polyethylene glycol (PEG); drought stress

\section{Introduction}

Stevia rebaudiana, commonly called "sweet leaf", is a perennial shrub distributed in South America mainly Brazil and Paraguay [1]. However, it is gaining remarkable significance all over the world because of its high potency sweetness. Rebaudioside A (Reb A) and stevioside (ST) are the major steviol glycosides (SGs) present in the leaf tissues of Stevia which are nonmutagenic and nontoxic compounds. The Stevia leaves are 300 times sweeter than sugar and have no calories [2,3]. SGs are multifunctional biochemicals and confer antidiabetic, antihypertensive, anti-inflammatory, and anticancerous properties 
to Stevia [4]. Seeds of S. rebaudiana show poor germination and the conventional propagation strategies such as cuttings are not effective [5]. Hence, new biotechnological approaches have been adopted for maximum production of Stevia progeny and its medicinal components in the minimum period of time [6-13].

Since the yield and production of secondary metabolites by traditional agriculture is not sufficient, plant tissue culture technique has been adapted as an alternative strategy to produce the commercially desired levels of bioactive compounds. Recently, medicinal plants have been exposed to different types of abiotic stresses leading to adaptive physiological changes and metabolic defence response signalling in the formation of secondary metabolites (extracellular or intracellular) to cope with the changing climatic conditions. Drought/dehydration is one of the abiotic stress elicitors against which tolerance can be evaluated using tissue culturing because the stress conditions get easily controlled under in vitro system. Moreover, least variability in plant population is observed in a limited time and space by the efficient tissue culture technique [14,15].

Polyethylene glycol (PEG) having molecular weight of 6000 is a natural polymer that is water-soluble and nonionic [16]. PEG 6000 is found to mimic drought stress and results in lowering of plant's water potential due to osmotic stress [17]. In the current study, physiological and metabolic changes in response to PEG 6000 were investigated as our understanding of the morphological and biochemical response of $S$. rebaudiana to drought stress is limited. According to the best of our knowledge, there is not a single study in which production of Reb A in response to PEG 6000-associated drought stress imposed under in vitro condition has been elaborated. Previously, Hajihashemi and Geuns [18] evaluated the impact of drought stress on SGs but under greenhouse cultivation system. Moreover, Badran et al. [19] determined the relationship between drought stress and ST content only. However, we conducted this study to explore water-deficit stress induced by PEG 6000 to in vitro grown S. rebaudiana shoots and evaluated the resultant effects on the physiology (plant biomass) and biochemistry $\{($ Reb A and ST content) and (antioxidation potential) $\}$ of S. rebaudiana by combating drought stress. Besides, it is a dire need to obtain sustainable secondary metabolites in bioreactors by modulating tissue culture-grown medicinal plants which can be achieved in the future by following up on this pilot research.

\section{Results}

\subsection{Evaluation of Growth and Development}

The shoots obtained from 4-week-old nodal explants cultivated in different MS growth medium treatments were observed. These treatments involved 0, 0.5, 1.0, 2.0, and 4.0\% of PEG 6000 stress. Table 1 shows that the maximum percentage of shooting ( 92.4\%) of nodal explants was revealed by the treatment containing $4 \%$ of PEG 6000 stress. Similarly, the maximum mean length of shoots $(5.1 \mathrm{~cm})$, mean number of nodes (5.3), mean number of leaves (17.9), and fresh weight (FW) of shoots (0.52 g) were found under the treatment supplemented with PEG stress of $4 \%$ concentration. It was followed by the results obtained from treatments containing 2, 1, and $0.5 \%$ of PEG 6000 concentration, respectively. The minimum percentage of shooting $(\sim 82.5 \%)$, mean shoots length $(4.1 \mathrm{~cm})$, mean number of nodes (4.4), mean number of leaves (13.1), and fresh weight (FW) of shoots ( $0.16 \mathrm{~g})$ were shown by the MS medium lacking PEG 6000, i.e., the control treatment. 
Table 1. Comparison of physiological parameters in 4-week-old shoots produced from nodal explants on Murashige and Skoog (MS) medium supplemented with different concentrations of PEG 6000.

\begin{tabular}{cccccc}
\hline $\begin{array}{c}\text { Conc. of } \\
\text { PEG } \\
(\%)\end{array}$ & $\begin{array}{c}\text { Nodal } \\
\text { Explants } \\
\text { Shooting (\%) }\end{array}$ & $\begin{array}{c}\text { Mean Shoot } \\
\text { Length } \\
\mathbf{( c m )}\end{array}$ & $\begin{array}{c}\text { Mean No. of } \\
\text { Nodes Per } \\
\text { Explant }\end{array}$ & $\begin{array}{c}\text { Mean No. of Leaves } \\
\text { Per Regenerated } \\
\text { Shoot }\end{array}$ & $\begin{array}{c}\text { FW of Shoots } \\
\text { Per Explant (g) }\end{array}$ \\
\hline 0 & 82.5 & $4.1 \pm 0.01^{\mathrm{e}}$ & $4.4 \pm 0.01^{\mathrm{e}}$ & $13.1 \pm 0.01^{\mathrm{c}}$ & $0.16 \pm 0.01^{\mathrm{d}}$ \\
0.5 & 84.7 & $4.3 \pm 0.01^{\mathrm{d}}$ & $4.6 \pm 0.01^{\mathrm{d}}$ & $13.6 \pm 0.02^{\mathrm{c}}$ & $0.24 \pm 0.01^{\mathrm{c}}$ \\
1.0 & 86.4 & $4.5 \pm 0.01^{\mathrm{c}}$ & $4.8 \pm 0.01^{\mathrm{c}}$ & $14.8 \pm 0.01^{\mathrm{b}}$ & $0.38 \pm 0.01^{\mathrm{b}}$ \\
2.0 & 88.9 & $4.7 \pm 0.02^{\mathrm{b}}$ & $5.0 \pm 0.01^{\mathrm{b}}$ & $16.5 \pm 0.02^{\mathrm{a}}$ & $0.45 \pm 0.01^{\mathrm{a}}$ \\
4.0 & 92.4 & $5.1 \pm 0.01^{\mathrm{a}}$ & $5.3 \pm 0.01^{\mathrm{a}}$ & $17.9 \pm 0.01^{\mathrm{a}}$ & $0.52 \pm 0.01^{\mathrm{a}}$ \\
\hline
\end{tabular}

$\pm:$ standard error, small alphabetical letters ${ }^{\text {a-e }}$ with mean values representing the difference among applied PEG concentration within the columns according to Duncan's multiple range test at confidence level of $95 \%$.

\subsection{Estimation of Secondary Metabolites Production}

Figure 1 shows that the content of SGs, i.e., Reb A and ST illustrated by HPLC were found highest (Reb A $2.94 \%$ and ST 2.52\%) under 4\% of PEG 6000 stress. However, the PEG-deficient treatment revealed lowest amount of SGs (Reb A $1.27 \%$ and ST 1\%).

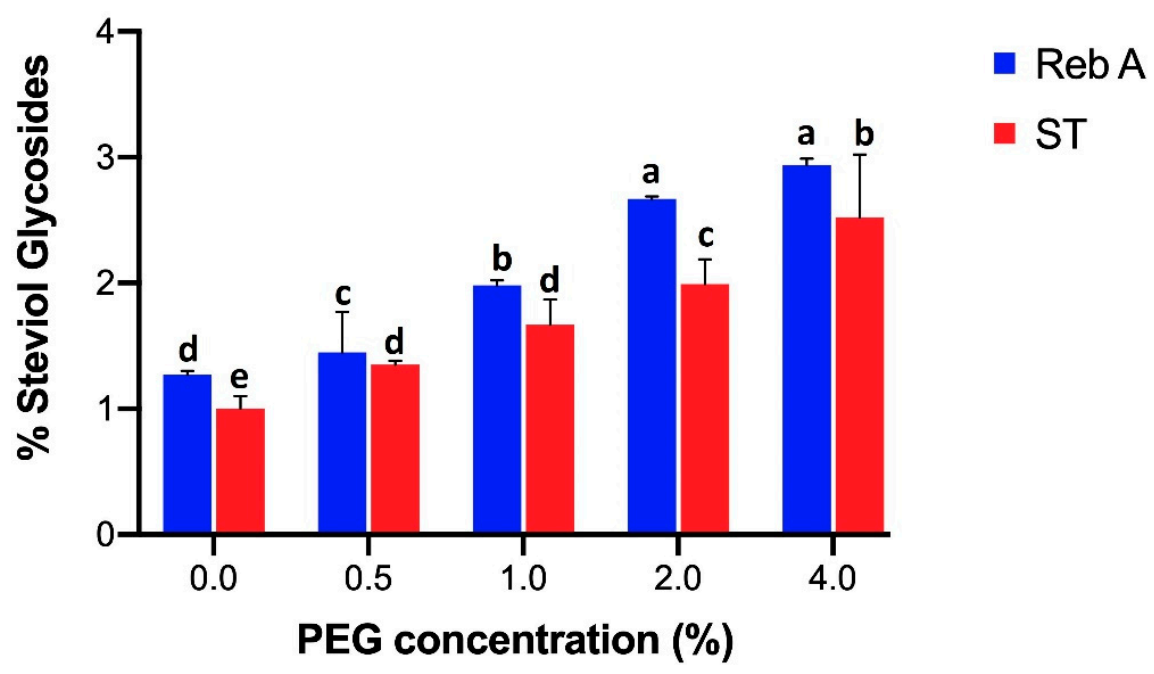

Figure 1. Effect of different PEG 6000 concentrations $(0,0.5,1,2,4 \%)$ on shoots regarding rebaudioside A content represented with blue bars and stevioside content with red bars. For each parameter, bars with different case letters a-e are significantly different at the confidence interval level of 95\% (Duncan's multiple range test).

In case of different nonenzymatic antioxidant activities such as TPC, TFC, TAC, TRP, and DPPH-FRSA, Figure 2a,b reveals that significantly highest content (TPC $15.03 \mu \mathrm{g} / \mathrm{mg}$, TFC $13.01 \mu \mathrm{g} / \mathrm{mg}$, TAC $22.26 \mu \mathrm{g} / \mathrm{mg}$, TRP $19.87 \mu \mathrm{g} / \mathrm{mg}$, and DPPH-FRSA 95.27\%) was estimated by the shoots grown in MS medium augmented with $4 \%$ of PEG 6000 stress. It was followed by the amounts obtained under the stress of $2 \%$ of PEG 6000 and later, 1\% of PEG 6000 stress, followed by the PEG 6000 stress of $0.5 \%$. The least quantity of antioxidant activities (TPC $6.97 \mu \mathrm{g} / \mathrm{mg}$, TFC $4.44 \mu \mathrm{g} / \mathrm{mg}$, TAC $13.7 \mu \mathrm{g} / \mathrm{mg}$, TRP $10.22 \mu \mathrm{g} / \mathrm{mg}$, and DPPH-FRSA $48.03 \%$ ) was elucidated by the shoots grown in PEG 6000-deficit medium. 


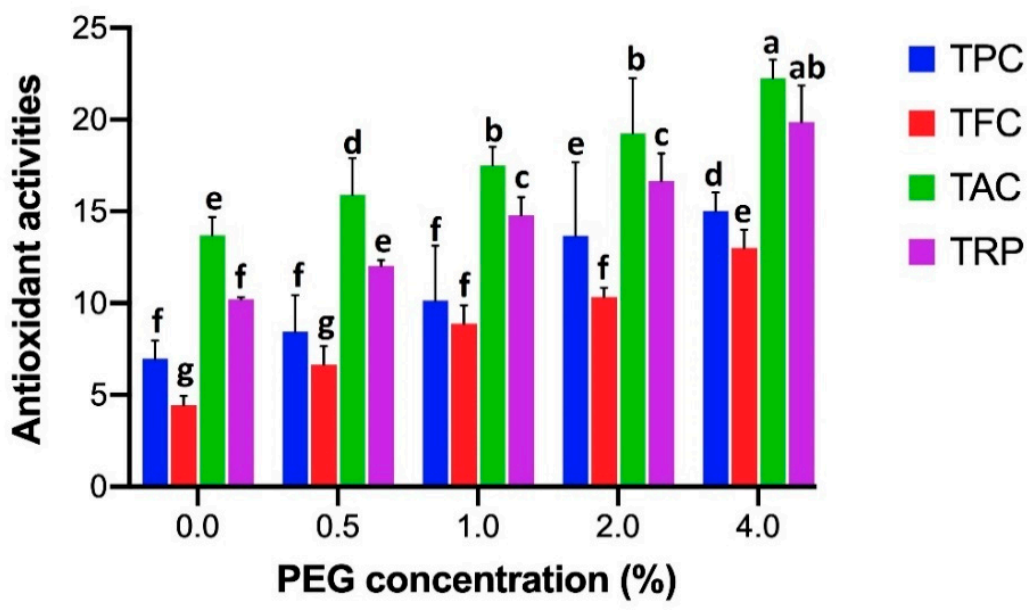

(a)

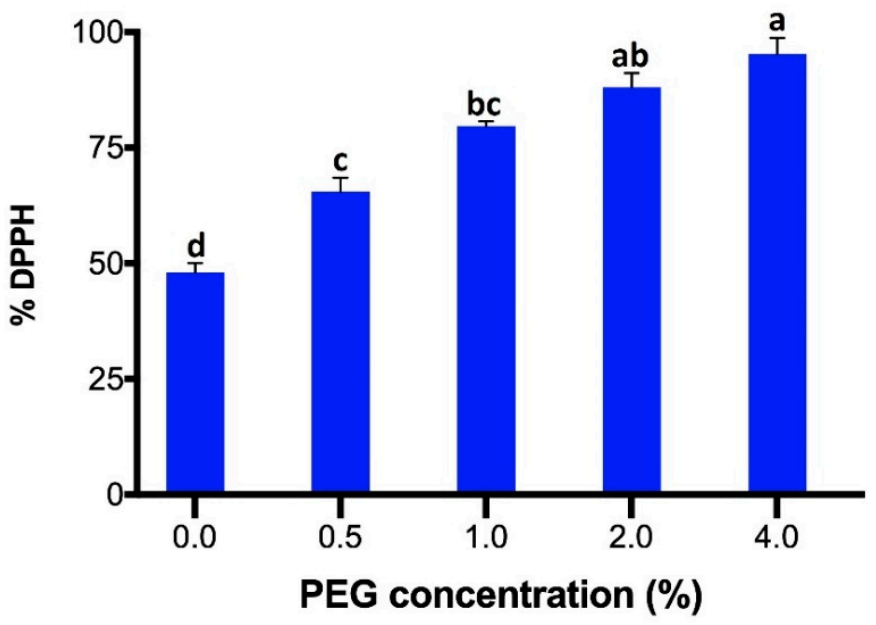

(b)

Figure 2. (a) Comparison of antioxidant activities (TPC, TFC, TAC, TRP) results expression for each assay of shoots grown under different PEG 6000 concentrations $(0,0.5,1,2,4 \%)$. For each parameter, bars with different case letters are significantly different at the confidence interval level of 95\% (Duncan's multiple range test). (b) Comparison of \% DPPH-free radical scavenging activity of shoots grown under different PEG 6000 concentrations (0, 0.5, 1, 2, 4\%). Bars with different case letters a-g are significantly different at the confidence interval level of $95 \%$ (Duncan's multiple range test).

\section{Discussion}

The current study outlines that differences in physiological characteristics, bioactive SGs content, and nonenzymatic antioxidant activities occur under the different concentrations of PEG 6000 stress; $0.5,1,1.5,2$, and $4 \%$. A significant increment of all these parameters has been observed from 0.5 to $4 \%$ of PEG 6000 concentration. Few previous reports have enlightened the enhancement of growth and antioxidants after exposure of S. rebaudiana to PEG 6000 while others disagree on the growth and secondary metabolites increase and ultimately susceptibility to water deficiency in the environment [18-24]. Hajihashemi and Ehsanpour [21] documented an increase in antioxidant activities of $S$. rebaudiana under rising levels of PEG 6000 concentration, i.e., 0, 2, 4, 6\%. Moreover, Hajihashemi and Sofo [20] reported reduction in plant growth but elevated levels of enzymatic and nonenzymatic antioxidants in this sweet herb under 5, 10, and 15\% of PEG 6000 concentration. Hajihashemi et al. [20] also elucidated enhancement of antioxidant activities in the callus of S. rebaudiana treated 
with PEG 6000 (0 and 4\%) along with different growth regulators. Additionally, Gorzi et al. [24] documented improved seedling growth and uprising antioxidant capacity upon exposure to PEG 6000 stress. These reports coincide with our study and prove the drought tolerance in S. rebaudiana on increasing PEG 6000 levels. On the contrary, Badran et al. [19] reported negative response of PEG 6000 stress on the ST production and positive response on shooting of $S$. rebaudiana. The plant shoots were exposed to different levels of PEG 6000, i.e., 0, 10, 20, $30 \mathrm{~g} / \mathrm{L}$ in their study and the ultimate result of exposure was marked decrease of stevioside with rising PEG 6000 concentration. The more recent studies by Bogado and Nakayama [23] and Pradhan et al. [25] reported that PEG 6000 induced a negative effect on the in vitro growth, whereas Hajihashemi and Geuns [18] demonstrated negative influence of PEG 6000 on SGs of S. rebaudiana. The later exposed Stevia to 5, 10, and 15\% PEG 6000 stress under greenhouse conditions and obtained results that are contradictory to our findings.

It is speculated that when drought stress is caused by water deficiency at critical levels, it manipulates the physiology as well as biochemistry of plants. In case of in vitro culture, S. rebaudiana plant cells imposed by PEG 6000 stress stimuli elicit significant alterations in the cellular environment. It involves activation of cellular receptors initiating signal transduction cascade that affects physiological processes. Changes in physiology influence primary metabolism that in turn causes signalling of secondary metabolism by providing biosynthetic precursors or intermediates. Hence, enhancement of biomass and bioactive components' biosynthesis takes place simultaneously as shown by the current study. The possible mechanism involves cellular dehydration caused by PEG 6000 stress and resultant increased formation of ROS. Multiple cellular components like DNA, RNA, proteins, and lipids get damaged after excessive oxidation. Although ROS are produced even in the absence of stress and get scavenged by naturally occurring antioxidant, the stress conditions cause imbalance of ROS and antioxidants produced in cross-protection. ROS are signalling moieties that play a significant role in the controlled response against stress and programmed cell death. The defensive response is created under appropriate concentration of stress elicitor whereas concentration above threshold causes death of cells [26-28].

The tools of molecular biology such as transcriptomic and metabolic technologies have been employed for the determination of stress associated genes and elucidation of signalling pathways. It has been speculated that the transcription factors responsible for regulation of gene expression of biosynthesis of secondary metabolites get activated in response to PEG 6000-associated drought stress $[18,29]$. Hence, tolerance produced by tolerance-associated molecules is implicated on cellular level that regulates different steps of signal transduction system. Despite recent advancement, extensive research is needed in this domain to elucidate the effects of drought stress on the secondary metabolites' formation and growth dynamics of the S. rebaudiana plant raised in vitro. Additionally, our current study should be applied on industrial scale to get enhanced content of desired pharmaceutical compounds by tissue culture.

\section{Experimental Procedure}

\subsection{MS Medium Preparation and Shoot Organogenesis Conditions}

The Murashige and Skoog (MS) culture medium [30] was prepared using 3\% (w/v) sucrose. In order to study organogenesis, 5 polyethylene glycol (PEG 6000) treatments, i.e., 0, 0.5, 1, 2, 4\% were prepared. $\mathrm{pH}$ of medium was adjusted to 5.7-5.8, and $0.8 \%(w / v)$ plant agar was added. The sterilization of medium was performed using autoclave at the pressure of $1.06 \mathrm{~kg} \mathrm{~cm}^{-2}$ and temperature of $121^{\circ} \mathrm{C}$ for $15 \mathrm{~min}$. 
The S. rebaudiana seeds purchased from Shenyang Agricultural University, China were first disinfected with $0.1 \%(w / v)$ of mercuric (II) chloride $\left(\mathrm{HgCl}_{2}\right)$. Then the culturing of these seeds was carried out on plain MS medium. The axillary shoot nodes excised from 4-week-old seedlings were incubated in various treatments of culture media. The growth room chamber having $16 \mathrm{~h}$ light $/ 8 \mathrm{~h}$ dark photoperiod, $35 \mu \mathrm{mol} \mathrm{m}^{-1} \mathrm{~s}^{-1}$ irradiance, $24 \pm 1{ }^{\circ} \mathrm{C}$ temperature, and $55-60 \%$ rate of relative humidity was utilized for conductance of experiment in triplicate. 15 explants per treatment were cultivated for 4 weeks. Various parameters of physiology, i.e., percentage (\%) of nodal explants shooting, mean shoots length, mean number of leaves per regenerated shoot, mean number of nodes per explant, and fresh weight (FW) of shoots per explant were observed.

\subsection{Extract Preparation for Steviol Glycosides Analysis}

The leaves of in vitro regenerated shoots from each treatment were utilized for extraction of steviol glycosides (SGs). After careful washing of all shoots with sterile distilled water, their soaking was done on filter paper. Then, the plant material was dried at $60^{\circ} \mathrm{C}$ for $48 \mathrm{~h}$ in an oven. The SGs were analysed by high performance liquid chromatography (HPLC) technique using Ultimate 3000 (Thermo Fisher, Temecula, CA, USA).

For HPLC, about $20 \mathrm{mg}$ of each sample treatment was added to microcentrifuge tube containing $1 \mathrm{~mL}$ of $70 \%(v / v)$ methanol. This solution was incubated in an ultrasonic bath at $55^{\circ} \mathrm{C}$ for $15 \mathrm{~min}$, and then centrifuged at $12,000 \mathrm{rpm}$ and $25^{\circ} \mathrm{C}$ for $10 \mathrm{~min}$. The supernatant was filtered using $0.22 \mu \mathrm{m}$ PTFE Millipore syringe filters and later on, HPLC analysis was done by running all of samples in triplicate.

HPLC analysis was performed using an autosampler (WPS-3000-SL Dionex Semi Prep Autosampler) injecting $10 \mu \mathrm{L}$ of each sample, a binary pump (LPG 3400SD Dionex) solvent delivery system working at a flow rate of $0.8 \mathrm{~mL} \mathrm{~min}^{-1}$, the column, Inertsil ${ }^{\circledR}$ ODS-3 (GL Sciences Inc. Tokyo, Japan) with $150 \times 4.6 \mathrm{~mm}$ in length and $5 \mu \mathrm{m}$ particle size that was kept warm at $40^{\circ} \mathrm{C}$ in a column oven system (TCC-3000SD Dionex, Watertown, MA, USA), and a dual wavelength absorbance detector operating at 210 and $350 \mathrm{~nm}$ (MWD-3100 Dionex UV-VIS Detector, Watertown, MA, USA). Finally, isocratic flow was performed using acetonitrile and $1 \%(w / v)$ phosphoric acid buffer mixture (68:32) for $20 \mathrm{~min}$.

Pure SGs $\left(100 \mathrm{mg} \mathrm{L}^{-1}\right)$ were spiked on the final plant extracts and the percentage of recovery was measured from two individual extractions and three analytical HPLC runs of each extract. The confirmation of SGs was done using a fraction collector system (AFC-3000 UltiMate Fraction Collector; Thermo-Fisher Scientific, Waltham, MA, USA) as well as by using a thin-layer chromatography system. The contents of SGs, i.e., Reb A and ST were determined on the basis of their molar absorption at $210 \mathrm{~nm}$ in which Reb A was also utilized for calibration purpose. The standard SGs were purchased from ChromaDex ${ }^{\circledR}$ (Irvine, CA, USA).

\subsection{Extract Preparation for Antioxidant Activities Analysis}

In order to perform different antioxidant activities, the $S$. rebaudiana leaf extracts were prepared by drying the leaves from different treatments at $100{ }^{\circ} \mathrm{C}$ in drying oven, and then taking $0.1 \mathrm{~g}$ of their fine powder that was dissolved in $500 \mu \mathrm{L}$ of dimethyl sulfoxide (DMSO). It was vortexed for $5 \mathrm{~min}$ and then sonicated for $30 \mathrm{~min}$. Centrifugation was performed at 10,000 rpm for $15 \mathrm{~min}$ and the supernatant was stored for performing antioxidant activities.

\subsubsection{Total Phenolic Content (TPC) and Total Flavonoid Content (TFC)}

In leaf extracts of $S$. rebaudiana, total phenol content (TPC) was determined by performing the method of Khan et al. [31]. An aliquot of $20 \mu \mathrm{L}(4 \mathrm{mg} / \mathrm{mL})$ of DMSO stock solution of each sample was added in the respective well of 96 well plate. Then, $90 \mu \mathrm{L}$ of Folin-Ciocalteu reagent was added in it and the plate was kept for $5 \mathrm{~min}$. Later, $90 \mu \mathrm{L}$ of sodium carbonate was added to the reaction mixture of all samples that were run in triplicate. The absorbance of samples was obtained at $630 \mathrm{~nm}$ using 
microplate reader. The standard used was gallic acid and the results were expressed as $\mu \mathrm{g}$ gallic acid equivalent per mg ( $\mu \mathrm{g} \mathrm{GAE} / \mathrm{mg}$ ).

Total flavonoid content (TFC) was determined by following the method of Khan et al. [31]. An aliquot of $20 \mu \mathrm{L}(4 \mathrm{mg} / \mathrm{mL})$ DMSO stock solution of each sample was added to the respective well of 96 well plate. Then, $10 \mu \mathrm{L}$ of $1.0 \mathrm{M}$ potassium acetate, $10 \mu \mathrm{L}$ of $10 \%$ aluminium chloride, and $160 \mu \mathrm{L}$ of distilled water were added to it and the mixture was kept at room temperature for $30 \mathrm{~min}$. The absorbance of samples run in triplicate was measured at $630 \mathrm{~nm}$ using microplate reader. The standard used was quercetin and the results were expressed as $\mu \mathrm{g}$ quercetin equivalent per $\mathrm{mg}$ ( $\mu \mathrm{g} \mathrm{QE} / \mathrm{mg}$ ).

\subsubsection{Total Antioxidant Capacity (TAC) and Total Reducing Power (TRP)}

Total antioxidant capacity (TAC) was determined by the method of Khan et al. [31]. An aliquot of $100 \mu \mathrm{L}$ from stock solution of each sample $(4 \mathrm{mg} / \mathrm{mL}$ in DMSO) was added to 96 -well plate and $900 \mu \mathrm{L}$ of reagent solutions containing $4 \mathrm{mM}$ ammonium molybdate, $0.6 \mathrm{M}$ sulfuric acid, and $28 \mathrm{mM}$ sodium phosphate were mixed in it. The solution was incubated at $95^{\circ} \mathrm{C}$ for $90 \mathrm{~min}$ and then cooled at room temperature. The absorbance of all samples run in triplicate was measured at $695 \mathrm{~nm}$ using microplate reader. Ascorbic acid was used as standard and the results were expressed as $\mu \mathrm{g}$ ascorbic acid equivalent per mg ( $\mu \mathrm{g} \mathrm{AA} / \mathrm{mg})$.

Total reducing power (TRP) was determined by following the method of Khan et al. [31]. An aliquot of $100 \mu \mathrm{L}$ of each sample ( $4 \mathrm{mg} / \mathrm{mL}$ in DMSO) was added to 96 -well plate and then $200 \mu \mathrm{L}$ of phosphate buffer $(0.2 \mathrm{M}, \mathrm{pH} 6.6)$ and $250 \mu \mathrm{L}$ of $1 \% w / v$ potassium ferricyanide were added to it. This mixture was incubated at $50{ }^{\circ} \mathrm{C}$ for $20 \mathrm{~min}$ and later acidified with $200 \mu \mathrm{L}$ of $10 \%(w / v)$ trichloroacetic acid. Centrifugation was performed at $3000 \mathrm{rpm}$ for $10 \mathrm{~min}$ and the supernatant $(150 \mu \mathrm{L})$ obtained was mixed with $50 \mu \mathrm{L}$ of $0.1 \%(w / v)$ ferric chloride solution. The absorbance of all samples run in triplicate was measured at $630 \mathrm{~nm}$. The standard used was ascorbic acid and results were expressed as $\mu \mathrm{g}$ ascorbic acid equivalent per mg ( $\mu \mathrm{g} \mathrm{AA} / \mathrm{mg})$.

\subsubsection{DPPH-Free Radical Scavenging Activity}

2,2-diphenyl-1-picryl hydrazyl (DPPH)-free radical scavenging activity (FRSA) activity was performed according to the method of Khan et al. [31]. An aliquot of $10 \mu \mathrm{L}(4 \mathrm{mg} / \mathrm{mL})$ of S. rebaudiana leaf extracts were added to 96 -well plate. $190 \mu \mathrm{L}$ of DPPH [0.004\% (w/v) in methanol] was added in it. This solution was incubated in darkness for $1 \mathrm{~h}$. The absorbance of all samples run in triplicate was observed at $515 \mathrm{~nm}$ using microplate reader. Ascorbic acid was used as positive control while DMSO was used as negative control.

$$
\% \text { inhibition of test sample }=\% \text { scavenging activity }=\left(1-\mathrm{A}_{\mathrm{bs}} / \mathrm{A}_{\mathrm{bc}}\right) \times 100
$$

where $A_{b s}$ indicates the absorbance of DPPH with sample and $A_{b c}$ is the absorbance of only DPPH. The $\mathrm{IC}_{50}$ was calculated by using Table curve software 2D Ver. 4 (SYSTAT, San Jose, CL, USA).

\subsection{Statistical Analysis}

The design of experiments was randomized, and the statistical analysis of data was performed using SPSS, Version 17.0 (SPSS Inc., Chicago, IL, USA). Statistical difference was determined using ANOVA and the significance of difference between means \pm SE (standard error) values was obtained using Duncan's multiple range tests performed at $p<0.05$.

\section{Conclusions}

This is the first report that brings to the spotlight how the major steviol glycosides (rebaudioside A and stevioside) respond when they get exposed to the abiotic stress induced by polyethylene glycol (PEG) 6000. Different growth parameters including percentage of explants shooting, mean shoots 
length, mean number of nodes, mean number of leaves, and fresh weight of shoots and antioxidant activities involving total phenolic content, total flavonoid content, total antioxidant capacity, total reducing power, and DPPH-free radical scavenging activity are also explored. Out of all concentrations, $4 \%$ of PEG concentration has been proved very efficacious in increasing the shoot organogenesis as well as the content of secondary metabolites in shoots of $S$. rebaudiana grown via tissue culture technique. Hence, this drought stress elicitor should be involved in further studies for significant enhancement and sustainable production of rebaudioside A and stevioside on commercial scale. Furthermore, signalling mechanisms of metabolic action of phenolic, flavonoid, and bioactive compounds produced by $S$. rebaudiana produced under drought stress should be finely investigated to unveil the ultimate reason for the described phenomenon.

Author Contributions: R.J. conceived the idea. M.A.A. did experimental work. R.J., M.A.A., M.A., and M.R. analysed the data and wrote the manuscript. Y.Y. provided all research facilities and funding. R.J. and Y.Y. were involved in the compilation of final draft and editing. All authors have approved the final version of manuscript.

Funding: This work was supported by National Key R\&D Program of China (2019YFC1804800), Key R\&D Program of Liaoning Province (2020JH2-10300083) and Shenyang Research and Development Program (Z17-5-079). The financial support was also provided to Muhammad Arslan Ahmad by Liaoning Government and from NSFC project (no. 41703126).

Acknowledgments: The technical support from Shenyang University is gratefully acknowledged.

Conflicts of Interest: The authors declare that they have no conflict of interest.

\section{Abbreviations}

MS, Murashige and Skoog; Reb A, rebaudioside A; ST, stevioside; DPPH, 2,2-diphenyl-1-picryl hydrazyl; HPLC, high performance liquid chromatography; TPC, total phenolic content; TFC, total flavonoid content; TAC, total antioxidant capacity; TRP, total reducing power; DMSO, dimethyl sulphoxide; ROS, reactive oxygen species.

\section{References}

1. Shivanna, N.; Naika, M.; Khanum, F.; Kaul, V.K. Antioxidant, anti-diabetic and renal protective properties of Stevia rebaudiana. Journal of Diabetes and its Complications 2013, 27, 103-113. [CrossRef] [PubMed]

2. Thiyagarajan, M.; Venkatachalam, P. Large scale in vitro propagation of Stevia rebaudiana (bert) for commercial application: Pharmaceutically important and antidiabetic medicinal herb. Industrial Crops and Products 2012, 37, 111-117. [CrossRef]

3. Gupta, P.; Sharma, S.; Saxena, S. Effect of abiotic stress on growth parameters and steviol glycoside content in Stevia rebaudiana (Bertoni) raised in vitro. Journal of Applied Research on Medicinal and Aromatic Plants 2016, 3, 160-167. [CrossRef]

4. Dey, A.; Kundu, S.; Bandyopadhyay, A.; Bhattacharjee, A. Efficient micropropagation and chlorocholine chloride induced stevioside production of Stevia rebaudiana Bertoni. C. R. Biol. 2013, 336, 17-28. [CrossRef]

5. Rafiq, M.; Dahot, M.U.; Muhamamd, S.; Naqvi, H.A.; Qarshi, I.A. In vitro clonal propagation and biochemical analysis of field established stevia Rebaudiana bertoni. Pak. J. Bot. 2007, 39, 2467-2474.

6. Javed, R.; Zia, M.; Yücesan, B.; Gürel, E. Abiotic stress of ZnO-PEG, ZnO-PVP, CuO-PEG and CuO-PVP nanoparticles enhance growth, sweetener compounds and antioxidant activities in shoots of Stevia rebaudiana Bertoni. IET Nanobiotechnology 2017, 11, 898-902. [CrossRef]

7. Javed, R.; Yucesan, B.; Zia, M.; Gurel, E. Differential effects of plant growth regulators on physiology, steviol glycosides content, and antioxidant capacity in micropropagated tissues of Stevia rebaudiana. Biologia 2017, 72, 1156-1165. [CrossRef]

8. Ahmad, M.A.; Javed, R.; Adeel, M.; Rizwan, M.; Ao, Q.; Yang, Y. Engineered ZnO and CuO Nanoparticles Ameliorate Morphological and Biochemical Response in Tissue Culture Regenerants of Candyleaf (Stevia rebaudiana). Molecules 2020, 25. [CrossRef]

9. Javed, R.; Mohamed, A.; Yücesan, B.; Gürel, E.; Kausar, R.; Zia, M. CuO nanoparticles significantly influence in vitro culture, steviol glycosides, and antioxidant activities of Stevia rebaudiana Bertoni. Plant Cell Tiss Organ Cult 2017, 131, 611-620. [CrossRef] 
10. Javed, R.; Usman, M.; Yücesan, B.; Zia, M.; Gürel, E. Effect of Zinc Oxide (ZnO) Nanoparticles on Physiology and Steviol Glycosides Production in Micropropagated Shoots of Stevia Rebaudiana Bertoni. Available online: https://pubmed.ncbi.nlm.nih.gov/27246994/ (accessed on 10 July 2020).

11. Javed, R.; Yücesan, B.; Gurel, E. Hydrogen Peroxide-Induced Steviol Glycosides Accumulation and Enhancement of Antioxidant Activities in Leaf Tissues of Stevia rebaudiana Bertoni. Sugar Tech 2018, 20, 100-104. [CrossRef]

12. Javed, R.; Yucesan, B.; Zia, M.; Gurel, E. Elicitation of Secondary Metabolites in Callus Cultures of Stevia rebaudiana Bertoni Grown Under ZnO and CuO Nanoparticles Stress. Sugar Tech 2018, 20, 194-201. [CrossRef]

13. Javed, R.; Gürel, E. Salt stress by $\mathrm{NaCl}$ alters the physiology and biochemistry of tissue culture-grown Stevia rebaudiana Bertoni. Turk. J. Agric. For. 2019, 43, 11-20. [CrossRef]

14. Mohd, K.K.; Pragati, M.; Taru, S.; Shukla, P.K.; Ramteke, P.W. Effect of adenine sulphate on in vitro mass propagation of Stevia rebaudiana Bertoni. J. Med. Plants Res. 2014, 8, 543-549. [CrossRef]

15. Espinosa-Leal, C.A.; Puente-Garza, C.A.; García-Lara, S. In vitro plant tissue culture: means for production of biological active compounds. Planta 2018, 248, 1-18. [CrossRef] [PubMed]

16. Ranjbarfordoei, A.; Samson, R.; Van Damme, P.; Lemeur, R. Effects of Drought Stress Induced by Polyethylene Glycol on Pigment Content and Photosynthetic Gas Exchange of Pistacia Khinjuk and P. Mutica. Photosynthetica 2000, 38, 443-447. [CrossRef]

17. Muscolo, A.; Sidari, M.; Anastasi, U.; Santonoceto, C.; Maggio, A. Effect of PEG-induced drought stress on seed germination of four lentil genotypes. Journal of Plant Interactions 2014, 9, 354-363. [CrossRef]

18. Hajihashemi, S.; Geuns, J.M.C. Gene transcription and steviol glycoside accumulation in Stevia rebaudiana under polyethylene glycol-induced drought stress in greenhouse cultivation. FEBS Open Bio 2016, 6, 937-944. [CrossRef]

19. Badran, A.E.; Alhady, M.R.A.A.; Hassan, W.A. In Vitro Evaluation of Some Traits in Stevia rebaudiana (Bertoni) under Drought Stress and Their Relationship on Stevioside Content. American Journal of Plant Sciences 2015, 6, 746-752. [CrossRef]

20. Hajihashemi, S.; Sofo, A. The effect of polyethylene glycol-induced drought stress on photosynthesis, carbohydrates and cell membrane in Stevia rebaudiana grown in greenhouse. Acta Physiol Plant 2018, 40, 142. [CrossRef]

21. Hajihashemi, S.; Ehsanpour, A.A. Antioxidant response of Stevia rebaudiana B. to polyethylene glycol and paclobutrazol treatments under in vitro culture. Appl. Biochem. Biotechnol. 2014, 172, 4038-4052. [CrossRef]

22. Hajihashemi, S.; Rajabpoor, S.; Djalovic, I. Antioxidant potential in Stevia rebaudiana callus in response to polyethylene glycol, paclobutrazol and gibberellin treatments. Physiol Mol Biol Plants 2018, 24, 335-341. [CrossRef]

23. Bogado Villalba, L.; Nakayama Nakashima, H. Effect of induced hydric stress with PEG 6000 on Stevia rebaudiana cv. "KH-IAN/VC-142" in vitro growth. Biotecnología Vegetal 2016, 16, 189-192.

24. Gorzi, A.; Omidi, H.; Bostani, A.B. Morpho-physiological responses of Stevia (Stevia rebaudiana Bertoni) to various priming treatments under drought stress. Appl. Ecol. Env. Res. 2018, 16, 4753-4771. [CrossRef]

25. Pradhan, N.; Singh, P.; Dwivedi, P.; Pandey, D.K. Evaluation of sodium nitroprusside and putrescine on polyethylene glycol induced drought stress in Stevia rebaudiana Bertoni under in vitro condition. Industrial Crops and Products 2020, 154, 112754. [CrossRef]

26. Laxa, M.; Liebthal, M.; Telman, W.; Chibani, K.; Dietz, K.-J. The Role of the Plant Antioxidant System in Drought Tolerance. Antioxidants (Basel) 2019, 8. [CrossRef]

27. Alhaithloul, H.A.; Soliman, M.H.; Ameta, K.L.; El-Esawi, M.A.; Elkelish, A. Changes in Ecophysiology, Osmolytes, and Secondary Metabolites of the Medicinal Plants of Mentha piperita and Catharanthus roseus Subjected to Drought and Heat Stress. Biomolecules 2020, 10. [CrossRef] [PubMed]

28. Said, E.M.; Rania A, M.; Rana Al, A.; Gehan, S. Drought Stress Tolerance and Enhancement of Banana Plantlets In Vitro. Austin J. Biotechnol. Bioeng. 2015, 2, 1040.

29. Liu, Y.; Meng, Q.; Duan, X.; Zhang, Z.; Li, D. Effects of PEG-induced drought stress on regulation of indole alkaloid biosynthesis in Catharanthus roseus. J. Plant Interact. 2017. [CrossRef] 
30. Murashige, T.; Skoog, F.K. A Revised Medium for Rapid Growth and Bio Assays with Tobacco Tissue Cultures. Physiol Plant 1962, 15. [CrossRef]

31. Khan, S.; Ur-Rehman, T.; Mirza, B.; Ul-Haq, I.; Zia, M. Antioxidant, Antimicrobial, Cytotoxic and Protein Kinase Inhibition Activities of Fifteen Traditional Medicinal Plants From Pakistan. Pharm Chem J 2017, 51, 391-398. [CrossRef]

Publisher's Note: MDPI stays neutral with regard to jurisdictional claims in published maps and institutional affiliations.

(C) 2020 by the authors. Licensee MDPI, Basel, Switzerland. This article is an open access article distributed under the terms and conditions of the Creative Commons Attribution (CC BY) license (http://creativecommons.org/licenses/by/4.0/). 